Published in final edited form as:

J Adolesc Health. 2015 May ; 56(5): 564-570. doi:10.1016/j.jadohealth.2015.01.018.

\title{
Selection of Branded Alcoholic Beverages by Underage Drinkers
}

\author{
Craig S. Ross, PhD, MBA ${ }^{a}$, Josh Ostroff ${ }^{a}$, Timothy S. Naimi, MD, MPH ${ }^{b, c}$, William DeJong, \\ $\mathbf{P h D}^{\mathrm{b}}$, Michael B. Siegel, MD, MPH ${ }^{\mathrm{b}}$, and David H. Jernigan, $\mathbf{P h D}^{\mathrm{d}}$ \\ aFiorente Media, Inc., Boston, MA 02111 USA \\ bDepartment of Community Health Sciences, Boston University School of Public Health, Boston, \\ MA 02218 USA \\ 'Section of General Internal Medicine, Boston Medical Center, Boston, MA 02118 USA \\ ${ }^{\mathrm{d} C e n t e r}$ on Alcohol Marketing and Youth, Department of Health, Behavior and Society, Johns \\ Hopkins Bloomberg School of Public Health, Baltimore, MD 21205
}

\begin{abstract}
Purpose-To identify reasons why youth choose to drink specific brands of alcohol and to determine if these reasons are associated with problem drinking patterns and outcomes.
\end{abstract}

\begin{abstract}
Methods-We conducted an Internet survey of 1,031 youth ages 13 to 20 who reported drinking within the past 30 days. Of these, 541 youth who reported having a choice of multiple brands of alcohol the last time they drank stated (yes/no) whether each of 16 different reasons had influenced their choice of a specific brand. We reduced these 16 reasons to three principle components and used Latent Class Modeling to identify five groups of youth with similar reasons for selecting a brand, which we then profiled.
\end{abstract}

Results-We grouped respondents into the following brand selection groups: "Brand Ambassadors" who were distinguished from other clusters by selecting a brand because they identified with it (32.5\% of respondents), "Tasters" who selected a brand because they expected it to taste good (27.2\%), "Bargain Hunters" who selected a brand because it was inexpensive (18.5\%), "Copycats" who selected a brand because they'd seen adults drinking it or seen it consumed in movies or other media (10.4\%), and "Others" (11.5\%). Brand Ambassadors and Copycats reported the largest amount of alcohol consumed and had the greatest prevalence of both heavy episodic drinking and negative alcohol-related health consequences.

Conclusions-Underage drinkers who cite marketing influences and adult or media modeling of brand choices as their reasons for selecting alcohol brands are likely to drink more and incur adverse consequences from drinking.

(C) 2015 Published by Society of Adolescent Health and Medicine.

Corresponding Author: Craig S. Ross, PhD, MBA, Fiorente Media, Inc., PO Box 727 Natick MA 01760 csr@ fiorentemedia.com USA 001 508-276-3422 x1717.

Publisher's Disclaimer: This is a PDF file of an unedited manuscript that has been accepted for publication. As a service to our customers we are providing this early version of the manuscript. The manuscript will undergo copyediting, typesetting, and review of the resulting proof before it is published in its final citable form. Please note that during the production process errors may be discovered which could affect the content, and all legal disclaimers that apply to the journal pertain. 


\section{Implications and Contribution}

Youth who cite marketing or modeling influences on their choice of alcoholic beverage brand drink more and suffer more adverse consequences. Measures should be taken to restrict youth exposure to alcohol marketing and promotion in the media and brand-specific counter-messaging should be part of prevention efforts.

\section{Introduction}

Alcohol is the leading risk factor for death and disability globally for persons ages 15 to 49 and from 2006-2010 was responsible for 4,358 deaths annually among persons under age 21 in the United States $(1,2)$. Early alcohol use by adolescents has been associated with increased risk for death and disability from motor vehicle crashes, violence, and suicide attempts (3-5). Further, underage alcohol consumption is associated with alcohol abuse and dependence, sexually transmitted infections, and unwanted pregnancies (5-8).

Even so, the use of alcohol by adolescents may also be perceived by some as a normative developmental process, as adolescents seek adult status, shift from parental to peer influence, and reject conformity in favor of individual expression (9-11). Media portrayals of alcohol use and alcohol advertisements contribute to these perceptions by shaping youth expectancies of alcohol use and modeling social contexts in which alcohol use is depicted as normative (12-14). Almost all alcohol advertising promotes a specific brand of alcohol, with the exception of a small number of advertisements that may promote regional production of an alcoholic product (e.g., wines of California or rums of Puerto Rico).

Recent research has explored mechanisms by which branded alcohol advertising may influence drinking behaviors. Morgenstern et al. (2011) showed that an adolescent's ability to identify masked alcohol advertisements was associated with drinking initiation both directly and through a change in attitudes toward alcohol. McClure et al. (2013) conceived of a model of alcohol marketing receptivity in which the ability to name a favorite brand of alcohol was used as a marker of high receptivity. The authors found high marketing receptivity mediated an association between alcohol advertising exposure and heavy episodic drinking, revealing mechanisms by which advertising may promote risky drinking. Morgenstern et al. (2014) used a similar model of marketing receptivity to replicate these results in a European sample of adolescents. Thus, the ability to identify specific brands through attributes portrayed in advertisements seems to be an important indicator of changes in youth attitudes towards alcohol.

Other research has found that exposure to alcohol promotional messages is associated with increased risk that adolescents initiate drinking, drink more if already drinking, and suffer negative health consequences from their alcohol use (15-17). Thus, research into the specific brands of alcohol being consumed by adolescents and their reasons for choosing these brands can contribute to our understanding of youth drinking and to the designing of prevention and harm reduction efforts.

We have identified the brands most frequently consumed by underage drinkers (18). These findings enable public health researchers to explore the influence of alcohol advertising and 
promotion on the underage drinker's brand choice. One study by the current authors found that brand-specific advertising was associated with increased drinking of the advertised brands (19), but questions remain about the role of advertising in brand choice when multiple brands are available to an underage drinker. Do underage drinkers exhibit sophisticated brand-seeking behaviors, selecting brands based on perceived brand attributes or benefits? Further, are different reasons for selecting a brand of alcohol associated with riskier drinking behaviors?

Answers to these questions may help to inform specific prevention efforts. Youth are exposed to an average of 366 alcohol advertisements on television each year (20). A growing percentage of these ads are from distilled spirits brands with higher concentrations of ethanol (higher proof). If alcohol advertising and "branding" are identified as reasons for choosing to drink higher proof alcohol, then it may be necessary to more strictly regulate advertising and promotion of these products and tailor counter-messaging and media literacy efforts to diminish these effects (9).

In this study we aim to (a) identify self-reported factors underlying alcohol brand selection among adolescents; (b) segment underage drinkers into groups who share similar reasons for choosing alcohol brands; and (c) profile each group on the basis of their alcohol consumption and other attributes.

\section{Methods}

\section{Study Population}

The ABRAND study consists of a national sample of 1,031 youth ages 13 to 20 drawn from the Knowledge Networks (GfK Custom Research) Internet Panel, all of whom reported drinking within the past 30 days. Details of the study sample, recruiting methods, and consent procedures have been published in detail elsewhere (18).

Briefly, members of the Knowledge Networks Panel ages 18 to 20 were contacted, screened for alcohol consumption in the past 30 days, and then asked to consent. Older panel members were asked if they had children ages 13 to 20 in the household. If so, the parents were asked to consent to their children being approached about participating. Children were then screened for past 30-day alcohol consumption and consented. After completion of the study, the participating panel members were credited \$25 toward their Knowledge Networks Panel account. The protocol was approved by the Institutional Review Board of the Boston University Medical Center.

A total of 1,031 respondents completed the study. The current study is restricted to those participants who reported they had a choice of different brands of alcohol the last time they drank. For those participants who reported that they had acquired the alcohol themselves, we selected into the current study those who answered "Yes" to the question: "When you got the alcohol that you most recently drank, did you attempt to get a specific brand of alcohol?" For those participants who reported that someone else acquired the alcohol, we selected into the current study those who answered "Yes" to the question: "Earlier in the survey, you indicated that when you most recently drank alcohol, someone else got the alcohol for you 
or that you did not know how you got the alcohol. When you most recently drank alcohol, did you have a choice of different brands to drink?" Our analysis sample consisted of 541 youth who reported having a choice of multiple brands of alcohol the last time they drank.

\section{Measures}

Demographics-Age is the participant's self-reported age at the time of the interview in years. Self-reported race and ethnicity were coded as non-Hispanic white, black, Hispanic, or other. For this analysis, we dichotomized race/ethnicity as non-Hispanic white versus all others. Household income was the self-reported income of the participant for those ages 18 to 20 in the following categories: less than $\$ 15,000 ; \$ 15,000$ to $\$ 39,999 ; \$ 40,000$ to $\$ 99,999$; and $\$ 100,000$ or more. For participants under age 18 , household income was reported by the parent using the same categories. For this analysis, we dichotomized household income at $\$ 40,000$.

Preferred Brand among Youth Drinkers-During the survey, participants identified all brands of alcohol they had consumed in the past 30 days, and which brand of alcohol they had chosen to drink first during their last drinking episode if more than one brand was available to them: "Which brand of alcohol did you choose to drink FIRST from among the available brands? If you mixed multiple brands in your FIRST drink, please select the one brand that you would usually prefer to drink." We classified these chosen brands by their alcoholic beverage type into one of four categories: beer (including malt liquor), flavored alcoholic beverages (including flavored malt beverages such as Smirnoff Ice or Mike's Hard Lemonade and wine coolers), distilled spirits (including pre-mixed cocktails containing spirits), and wine (including sparkling wine).

Reasons for Selecting a Brand of Alcohol-Participants reported (yes/no) whether each of the following 16 different reasons had influenced their choice of the first brand they drank: 1) "I have seen celebrities drink this brand" 2) "Good things happen to people who drink this brand" 3) "I like the advertising for this brand" 4) "I have seen people drink this brand in movies, on the Internet, on television, or in other media" 5) "I own clothing or other products with this brand's name or logo" 6) "People my age I admire drink this brand" 7) "I identify with this brand" 8) "A friend or sibling recommended it to me" 9) "I thought it would taste good" 10) "I have seen other people my age drinking this brand" 11) "I have seen my parents or other adults drinking this brand" 12) "I have previously drunk it and I like it" 13) "My close friends drink this brand" 14) "It is easy to get" 15) "It is inexpensive" 16) "It's pretty much the same as other brands."

Drinking Behaviors-Each respondent reported the total number of standard drinks consumed during the past 30 days. A standard drink contains approximately 14 grams of pure alcohol and respondents were presented with a graphic image of different drinking containers and glasses with the corresponding number of standard drinks associated with each. The average number of drinks per drinking occasion was calculated by summing the total drinks of each brand of alcohol consumed and dividing by the number of drinking occasions. The number of drinking days per month was calculated by summing the number of drinking days during the 30-day reference period. Heavy episodic drinking was a 
dichotomous variable defined as any report of consumption of 5 or more alcoholic beverages consumed in a row. Number of brands consumed was the total number of different brands of alcohol consumed in the 30-day reference period. Money spent on alcohol in the past 30 days was dichotomized at amounts above $\$ 25$.

Alcohol Cognitions-Respondents expressed their opinion about the role of advertising (5-point scale ranging from "Strongly Disagree" to "Strongly Agree"): 1) "Advertisements help me decide whether to drink or not"; 2) "Advertisements help me decide what brand of alcohol to drink." Using the same Likert scale, we assessed alcohol expectancies with a subset of the Alcohol Expectancy Questionnaire (21): 1) "Drinking alcohol is fun"; 2) "Drinking alcohol helps me gain friends"; 3) "Drinking alcohol helps me talk to others." We summed these three expectancy responses to create a total expectancy score (Cronbach's alpha 0.81).

Risk Behaviors and Drinking Consequences-We asked respondents how frequently they experienced any of the following drinking consequences in the past year (never, once, twice, 3 or 4 times, 5 or more times): 1) "got into a physical fight while or after drinking"; 2) "had an injury where any part of your body was hurt while or after drinking"; 3) "had an injury serious enough that a medical professional was consulted." We dichotomized the responses as once or more vs. never and then summed each respondent's answers into a single consequences scale (Cronbach's alpha 0.80).

We asked about two risk behaviors: 1) the frequency of wearing a seatbelt ("never", "rarely", "sometimes", "most of the time", "always," which we dichotomized as less than "most of the time" vs. "most of the time" or "always") and 2) past 30-day smoking (yes/no).

Television and Magazine Alcohol Advertising Exposure-Respondents reviewed a list of 20 television programs that heavily advertised alcohol and checked off each show they had watched in the past 30 days. Similarly, they reviewed a list of 20 magazines that heavily advertised alcohol and checked off those they had read any part of in the past 30 days. We calculated the total number of television shows viewed and total number of magazines read.

\section{Analyses}

We calculated frequencies for each of the reasons given for choosing a specific brand of alcohol and then conducted a principle component analysis to reduce these reasons to a smaller set of components. The number of principal components was chosen by selecting those components with an eigenvalue greater than one. The resulting three principal components were used to create an orthogonal 3-dimensional space into which each participant was mapped based on their component scores. Specifically, each participant was coded as low/medium/high on each of the three principal components and then these values were used as input to a Latent Class Analysis (22) to identify groups of respondents that clustered in that space. We determined the number of groups for the Latent Class Model by selecting the model with the smallest number of parameters that was statistically significant (alpha=0.05) using a bootstrap likelihood ratio chi-square test (22) and which demonstrated 
the best fit using the Bayesian Information Criterion (BIC). Finally, we profiled the clusters by performing all possible pairwise comparisons (F-tests for continuous variables and chisquare tests for proportions) between attributes in each cluster using a Bonferonni-adjusted statistical significance cutoff value of 0.005 .

\section{Results}

The 541 respondents who reported having a choice of different alcohol brands the last time they drank did not differ from the entire sample on any demographic factor. They did report more drinking activity, with both a higher number of drinking days per month (Mean \pm StDev $6.4 \pm 5.8$ vs. $5.1 \pm 5.4$ ) and a greater number of drinks consumed ( $26.4 \pm 35.6$ vs. $19.9 \pm 31.0)$. A higher percentage of these respondents also reported at least one episode of heavy episodic drinking in the last 30 days (63.0\% vs. $51.5 \%)$.

Reasons for choosing a particular brand of alcohol and rotated component loadings from the principal component analysis are presented in Table 1. The most common reasons for choosing a particular brand were familiarity with the brand ("I have previously drunk it and I like it") and expectations about the taste ("I thought it would taste good"). The sixteen brand choice reasons were reduced to three principal components that explained $62 \%$ of the total variance: a "branding" component, a "modeling" component, and a "convenience" component.

Table 2 contains summaries of model fit for Latent Class Models with 1 to 6 clusters. The bootstrap p-value for 6 clusters was not significant, and the Bayesian Information Criterion showed the best fit for 5 clusters. Therefore we settled on a five-cluster solution.

Tables $3 a-3 b$ show the concentration of the three brand selection principal components (3a) and signature brand selection reasons ( $3 b$ ) in each group. The principle component concentrations (3a) are expressed as an index showing the actual proportion of high/ medium/low participants relative to $20 \%$ (the proportion expected under a null hypothesis of equal distribution across all groups). The signature reasons (3b) are simply the highest proportion responses of brand selection reasons in each group.

As shown in Table 3, participants who scored high on the branding component were highly concentrated in groups A and D; participants who scored high on the modeling component were highly concentrated in groups B and D; participants who scored high on the convenience component were highly concentrated in group C.

Participants in Group A (32.5\% of sample) were most likely to select a brand of alcohol because they identified with the brand or because they expected good things to happen to people who drink the brand. Thus, we named this group "Brand Ambassadors." Participants in Group B (27.2\%) were most likely to select a brand because they thought it would taste good, hence the name "Tasters." Group C "Bargain Hunters" (19.0\%) were most likely to select a brand a brand because it was inexpensive. Group D participants ("Copycats", $10.4 \%$ ) were most likely to select a brand because they have seen an adult drinking it, because they saw it consumed in media, or because they owned branded merchandise for 
this product. Finally, the last group (11.5\%) did not provide any signature reason for choosing a brand; we refer to them as "Others."

\section{Attributes of Brand Selection Groups}

Global tests showed that all attributes differed among the brand selection groups (Table 4). Using pairwise comparisons, we found both Brand Ambassadors and Tasters to be older than Bargain Hunters and Others. Bargain Hunters were more likely to be female than Brand Ambassadors, Tasters, or Others. Others were more likely to be non-White than Tasters. Finally, Tasters were higher income than Brand Ambassadors or Copycats.

Brand Ambassadors and Copycats reported more heavy episodic drinking than Tasters and Copycats also reported more heavy episodic drinking than Bargain Hunters and Others. Both Brand Ambassadors and Copycats reported more total drinks than Tasters and Copycats also reported more total drinks than Others. Brand Ambassadors and Copycats drink more brands than the other three groups. Finally, Brand Ambassadors spent more money on alcohol than Tasters, Bargain Hunters, or Others.

Brand Ambassadors were more likely than Tasters to report that advertising influenced their decision to drink and their choice of brands. Both Brand Ambassadors and Copycats reported more positive drinking expectancies than either Bargain Hunters or Others. Brand Ambassadors reported more health consequences than Tasters, while Copycats reported more consequences than either Tasters or Bargain Hunters. Finally, Brand Ambassadors watched more TV shows with alcohol advertisements than either Bargain Hunters or Tasters, Copycats more than Bargain Hunters, and Tasters more than Bargain Hunters. Both Brand Ambassadors and Copycats reported reading more magazines with alcohol advertising than Tasters or Bargain Hunters.

To summarize, Brand Ambassadors and Copycats reported the greatest exposure to media with alcohol advertising and had a higher prevalence of risky drinking behaviors and drinking consequences than the other brand selection groups.

\section{Discussion}

Underage drinkers who cite marketing influences and adult or media modeling of brand choices as their reasons for selecting alcohol brands drink more and incur more adverse consequences from drinking relative to other youth. Most youth reported selecting a brand of alcohol because they were familiar with it, but when we examined additional factors that drive brand selection, we found important distinctions between different groups of youth. Two groups, Brand Ambassadors and Copycats, acknowledged being influenced by alcohol advertisements, media portrayals of alcohol use, and celebrity endorsements in addition to peer and parent influences. The prevalence of abusive drinking among these two groups and the high rates of negative health consequences reported by Copycats should be of particular concern.

Prior research has shown associations among underage drinkers between exposure to alcohol advertising and drinking initiation, and between exposure to alcohol advertising and 
promotion and higher drinker levels $(15,17)$. Alcohol portrayals in film and exposure to alcohol imagery and lyrics in music videos have also been associated with drinking behaviors (23-25). Further, a report of having a favorite brand of alcohol has been shown to be a mediator between exposure to alcohol marketing and heavy episodic drinking (26). None of this previous research examined the reasons for selecting specific brands.

Alcohol advertisements have been shown to portray lifestyles and social contexts in which alcohol is a key ingredient (27-30). In marketing parlance, the association of a product with a particular lifestyle or social benefit is called "branding" (31). In particular, brand "intangibles" are those "aspects of the brand image that do not involve physical, tangible, or concrete attributes" of the product (31). For example, Dos Equis' very successful "Most Interesting Man in the World" campaign established a link between mystique, masculinity, and sex appeal, and a beer that would otherwise be promoted on the basis of concrete attributes such as taste (32). Other alcohol brands are affiliated with skullduggery (Captain Morgan Rums), sports fanaticism (Bud Light Beer), tropical paradises (Corona Extra Beer), Caribbean party themes (Malibu Rum), and elegant night life (Ciroc Vodka). Adolescents who are experimenting with different identities, and who may have cognitive deficits with respect to this type of advertising, may be particularly vulnerable to these messages $(14,33-$ 35). In our study, we found that more than a quarter of underage drinkers who had a choice of multiple brands the last time they consumed alcohol chose a specific brand to drink at least in part because they identified with the brand, liked the advertising, or saw people in the media consuming it.

It may be impossible to separate the act of drinking from the branding and social contexts that have been created by alcohol companies and distributors, media companies, sports leagues, and other entertainment related businesses to facilitate drinking. Currently the American Academy of Pediatrics' policy statement on underage drinking supports media literacy training for medical practitioners and calls for advocacy to promote "appropriate media modeling of alcohol consumption and [its] consequences" (36). Given the sophistication of modern marketing techniques, such efforts may be inadequate to the task at hand.

Media literacy training should not be limited to medical practitioners, rather physicians should have resources to which they can refer their patients and families so that they can be better equipped to handle pervasive brand messaging and to understand the importance of adult and media modeling of drinking contexts and behaviors. Media literacy programs should be included in school curricula and the power of the internet should be utilized to make media literacy and counter-messaging tools available to all.

Perhaps more importantly, youth exposure to pervasive alcohol marketing and promotion needs to be reduced, as recommended by the World Health Organization and the National Research Council/Institute of Medicine (37, 38). In the United States, because commercial free speech is protected, effective counter-messaging would need to be produced on a scale sufficient to have an impact (39). 
This study is subject to several limitations. First, the study is cross-sectional and therefore the direction of the association between brand selection and advertising or media influences cannot be ascertained. Second, this analysis was conducted on a subset of the national sample, specifically those respondents who had a choice of more than one brand of alcohol the last time they drank. While these respondents did not differ from the full sample on any demographic characteristics, they were found to drink at higher levels. Therefore, these findings may be more representative of heavier-drinking youth.

Third, due to the length of the survey, we limited respondents to a yes/no response to each brand selection reason instead of using a Likert-type response scale. Changes in scale measures could slightly modify the brand selection components and thereby the resulting respondent groups. Future research should examine these associations using more refined measurement scales.

Fourth, the phrasing of our questions related to seatbelt use and negative consequences of alcohol consumption referred to periods prior to the time window in which we assessed current drinking of branded beverages. Finally, youth recall of brand choices made over the past thirty days may be subject to recall errors and there may be some additional reasons for brand choice not revealed by underage drinkers in this study.

Alcohol is unlike other commodities promoted through the media (40). Alcohol use ranks among the top five causes of all deaths globally and it is the leading risk factor contributing to the burden of disease globally for young persons (2). Evidence continues to mount that youth exposure to alcohol advertising and promotion is associated with higher risk of alcohol initiation, drinking, abuse, and, now, brand selection among young persons. It is incumbent upon public health researchers and advocates to investigate and promote prevention measures that can offset the negative influence of alcohol marketing and promotion on our children's health. More effective restrictions on advertising placement are needed to reduce youth exposure to alcohol marketing and promotion, thereby alleviating the risk young people face from this marketing.

\section{Acknowledgments}

This research was supported by a grant from the National Institute on Alcohol Abuse and Alcoholism (R01 AA020309-01). Craig Ross' participation in this study was supported in part by grant NIH T32 HD052458 (Boston University Reproductive, Perinatal and Pediatric Epidemiology training program). Additional funding was provided by Cooperative Agreement Number 5U58DP002027 from The Centers for Disease Control and Prevention. The funders had no role in the design or conduct of the study; the collection, management, analysis, or interpretation of the data; the preparation, review, or approval of the manuscript; or the decision to submit the manuscript for publication. The contents of this paper are solely the responsibility of the authors and do not necessarily represent the official views of the Centers for Disease Control and Prevention or the National Institutes of Health. The authors thank James D. Sargent, MD, S. Jean Emans, MD, Elizabeth Woods MD MPH, and David S. Bickham, $\mathrm{PhD}$ for their comments on the manuscript. The subject matter of this manuscript was presented at the Society of Adolescent Health and Medicine Annual Meeting in Austin, TX in March 2014.

\section{References}

1. Centers for Disease Control and Prevention. [Accessed October 7, 2014] Alcohol Related Disease Impact (ARDI) application. Available at: http://apps.nccd.cdc.gov/DACH_ARDI/Default.aspx

2. Lim SS, Vos T, Flaxman AD, et al. A comparative risk assessment of burden of disease and injury attributable to 67 risk factors and risk factor clusters in 21 regions, 1990-2010: a systematic 
analysis for the Global Burden of Disease Study 2010. Lancet. 2012; 380:2224-2260. [PubMed: 23245609]

3. Swahn MH, Bossarte RM, Sullivent EE 3rd. Age of alcohol use initiation, suicidal behavior, and peer and dating violence victimization and perpetration among high-risk, seventh-grade adolescents. Pediatrics. 2008; 121:297-305. [PubMed: 18245421]

4. Hingson RW, Edwards EM, Heeren T, et al. Age of drinking onset and injuries, motor vehicle crashes, and physical fights after drinking and when not drinking. Alcoholism, clinical and experimental research. 2009; 33:783-790.

5. Hingson R, Heeren T, Zakocs R. Age of drinking onset and involvement in physical fights after drinking. Pediatrics. 2001; 108:872-877. [PubMed: 11581438]

6. Grant BF, Dawson DA. Age at onset of alcohol use and its association with DSM-IV alcohol abuse and dependence: Results from the National Longitudinal Alcohol Epidemiology Survey. Journal of Substance Abuse. 1997; 9:103-110. [PubMed: 9494942]

7. Hingson R, Heeren T, Winter MR, et al. Early age of first drunkenness as a factor in college students' unplanned and unprotected sex attributable to drinking. Pediatrics. 2003; 111:34-41. [PubMed: 12509551]

8. Stueve A, O'Donnell LN. Early alcohol initiation and subsequent sexual and alcohol risk behaviors among urban youths. American journal of public health. 2005; 95:887-893. [PubMed: 15855470]

9. Fischhoff B, Quadrel MJ. Adolescent alcohol decisions. Alcohol Health \& Research World. 1991; $15: 43-43$.

10. Franzkowiax P. Risk-taking and adolescent development: The functions of smoking and alcohol consumption in adolescence and its consequences for prevention. Health Promotion International. $1987 ; 2: 51-62$.

11. Jessor R, Jessor SL. Adolescent development and the onset of drinking. A longitudinal study J Stud Alcohol. 1975; 36:27-51.

12. Austin EW, Chen MJ, Grube JW. How does alcohol advertising influence underage drinking? The role of desirability, identification and skepticism. The Journal of adolescent health : official publication of the Society for Adolescent Medicine. 2006; 38:376-384. [PubMed: 16549298]

13. Austin EW, Meili HK. Effects of interpretations of televised alcohol portrayals on children's alcohol beliefs. Journal of Broadcasting \& Electronic Media. 1994; 38:417-417.

14. Grube JW, Wallack L. Television beer advertising and drinking knowledge, beliefs, and intentions among schoolchildren. American journal of public health. 1994; 84:254-259. [PubMed: 8296950]

15. Smith LA, Foxcroft DR. The effect of alcohol advertising, marketing and portrayal on drinking behaviour in young people: systematic review of prospective cohort studies. BMC public health. 2009; 9:1-11. [PubMed: 19121216]

16. Grenard JL, Dent CW, Stacy A. Exposure to Alcohol Advertisements and Teenage AlcoholRelated Problems. Pediatrics. 2013; 131:e369-e379. [PubMed: 23359585]

17. Anderson P, de Bruijn A, Angus K, et al. Impact of alcohol advertising and media exposure on adolescent alcohol use: a systematic review of longitudinal studies. Alcohol and Alcoholism. 2009; 44:229-243. [PubMed: 19144976]

18. Siegel M, DeJong W, Naimi TS, et al. Brand-Specific Consumption of Alcohol Among Underage Youth in the United States. Alcoholism: Clinical and Experimental Research. 2013; 37:11951203.

19. Ross CS, Maple E, Siegel M, et al. The Relationship Between Brand-Specific Alcohol Advertising on Television and Brand-Specific Consumption Among Underage Youth. Alcoholism, clinical and experimental research. 2014; 38:2234-2242.

20. CAMY. Youth Exposure to Alcohol Advertising on Television, 2001-2009. Baltimore, MD: Center on Alcohol Marketing and Youth at Johns Hopkins University Bloomberg School of Public Health; 2010 Dec 15.

21. Christiansen BA, Goldman MS, Inn A. Development of alcohol-related expectancies in adolescents: Separating pharmacological from social-learning influences. Journal of consulting and clinical psychology. 1982; 50:336-344. [PubMed: 7096736] 
22. Magidson, J.; Vermunt, JK. Latent Class Models. In: Kaplan, D., editor. The Sage Handbook of Quantitative Methodology for the Social Sciences. Thousand Oaks, CA: Sage Publications; 2004. p. $175-198$.

23. Hanewinkel R, Sargent JD. Longitudinal study of exposure to entertainment media and alcohol use among german adolescents. Pediatrics. 2009; 123:989-995. [PubMed: 19255030]

24. Hanewinkel R, Tanski SE, Sargent JD. Exposure to alcohol use in motion pictures and teen drinking in Germany. International journal of epidemiology. 2007; 36:1068-1077. [PubMed: 17586537]

25. van den Bulck J, Beullens K. Television and music video exposure and adolescent alcohol use while going out. Alcohol and alcoholism (Oxford, Oxfordshire). 2005; 40:249-253.

26. McClure AC, Stoolmiller M, Tanski SE, et al. Alcohol marketing receptivity, marketing-specific cognitions, and underage binge drinking. Alcoholism, clinical and experimental research. 2013; 37 (Suppl 1):E404-413.

27. Finn TA, Strickland DE. A content analysis of beverage alcohol advertising II: Television advertising. J Stud Alcohol. 1982; 43:964-989. [PubMed: 7166963]

28. Jones SC, Donovan RJ. Messages in alcohol advertising targeted to youth. Australian and New Zealand Journal of Public Health. 2001; 25:126-131. [PubMed: 11357907]

29. Mosher JF, Wallack L. Government Regulation of Alcohol Advertising: Protecting Industry Profits versus Promoting Public Health. Journal of public health policy. 1981; 2:333-353. [PubMed: 7334125]

30. Strickland DE, Finn TA, Lambert MD. A content analysis of beverage alcohol advertising I. Magazine advertising J Stud Alcohol. 1982; 43:655-682.

31. Keller KL, Lehmann DR. Brands and Branding: Research Findings and Future Priorities. Marketing Science. 2006; 25:740-759.

32. Schultz, EJ. Advertising Age. New York, NY: Advertising Age; 2010. America's Hottest Brands 2010: Dos Equis, Paul Smailes Brand Director.

33. Brown SA, McGue M, Maggs J, et al. Underage Alcohol Use. Alcohol Research \& Health. 2009; 32:41-52. [PubMed: 23104446]

34. Collins RL, Ellickson PL, McCaffrey DF, et al. Saturated in beer: awareness of beer advertising in late childhood and adolescence. The Journal of adolescent health : official publication of the Society for Adolescent Medicine. 2005; 37:29-36. [PubMed: 15963904]

35. Masten AS, Faden VB, Zucker RA, et al. A Developmental Perspective on Underage Alcohol Use. Alcohol Research \& Health. 2009; 32:3-15. [PubMed: 23104443]

36. American Academy of Pediatrics. Policy Statement - Alcohol Use by Youth and Adolescents: A Pediatric Concern. Pediatrics. 2010; 125:1078-1087. [PubMed: 20385640]

37. Bonnie, RJ.; O’Connell, ME. Reducing Underage Drinking: A Collective Responsibility. Washington, D.C: National Academies Press; 2004.

38. World Health Organization. Global strategy to reduce the harmful use of alcohol. Geneva: World Health Organization; 2010.

39. Saffer H. Alcohol Advertising and Youth. J Stud Alcohol. 2002; (Supplement 14):173-181.

40. Babor, T.; Caetano, R.; Casswell, S., et al. Alcohol: No Ordinary Commodity. 2. New York, NY: Oxford University Press; 2010. 


\section{Table 1}

Reasons for Choosing a Specific Brand of Alcohol in the Presence of Multiple Brands during Underage Drinkers' Last Drinking Occasion

\begin{tabular}{|c|c|c|c|c|}
\hline \multirow[b]{2}{*}{ Reasons for Choosing a Specific Brand } & \multirow[b]{2}{*}{ Percent of Respondents } & \multicolumn{3}{|c|}{ Rotated Components and Loadings* } \\
\hline & & Branding & Modeling & Convenience \\
\hline I have seen celebrities drink this brand & 15.8 & 0.78 & 0.07 & 0.19 \\
\hline Good things happen to people who drink this brand & 11.8 & 0.75 & 0.06 & 0.09 \\
\hline I like the advertising for this brand & 30.3 & 0.68 & 0.22 & 0.28 \\
\hline $\begin{array}{l}\text { I have seen people drink this brand in movies, on the Internet, on } \\
\text { television, or in other media }\end{array}$ & 25.1 & 0.66 & 0.21 & 0.18 \\
\hline I own clothing or other products with this brand's name or logo & 10.2 & 0.62 & 0.37 & -0.30 \\
\hline People my age I admire drink this brand & 26.7 & 0.58 & 0.36 & 0.18 \\
\hline I identify with this brand & 30.8 & 0.54 & 0.11 & 0.49 \\
\hline A friend or sibling recommended it to me & 54.6 & 0.10 & 0.81 & 0.14 \\
\hline I thought it would taste good & 82.5 & 0.18 & 0.70 & 0.49 \\
\hline I have seen other people my age drinking this brand & 67.4 & 0.25 & 0.70 & 0.42 \\
\hline I have seen my parents or other adults drinking this brand & 41.1 & 0.17 & 0.67 & 0.09 \\
\hline I have previously drunk it and I like it & 81.1 & 0.28 & 0.62 & 0.50 \\
\hline My close friends drink this brand & 59.5 & 0.36 & 0.53 & 0.49 \\
\hline It is easy to get & 65.1 & 0.22 & 0.49 & 0.63 \\
\hline It is inexpensive & 46.1 & 0.06 & 0.25 & 0.79 \\
\hline It's pretty much the same as other brands & 31.2 & 0.17 & 0.16 & 0.64 \\
\hline
\end{tabular}

* Principal components analysis of 16 brand selection reasons with varimax rotation. Brand selection reasons that load highly onto each principal component are bolded. 

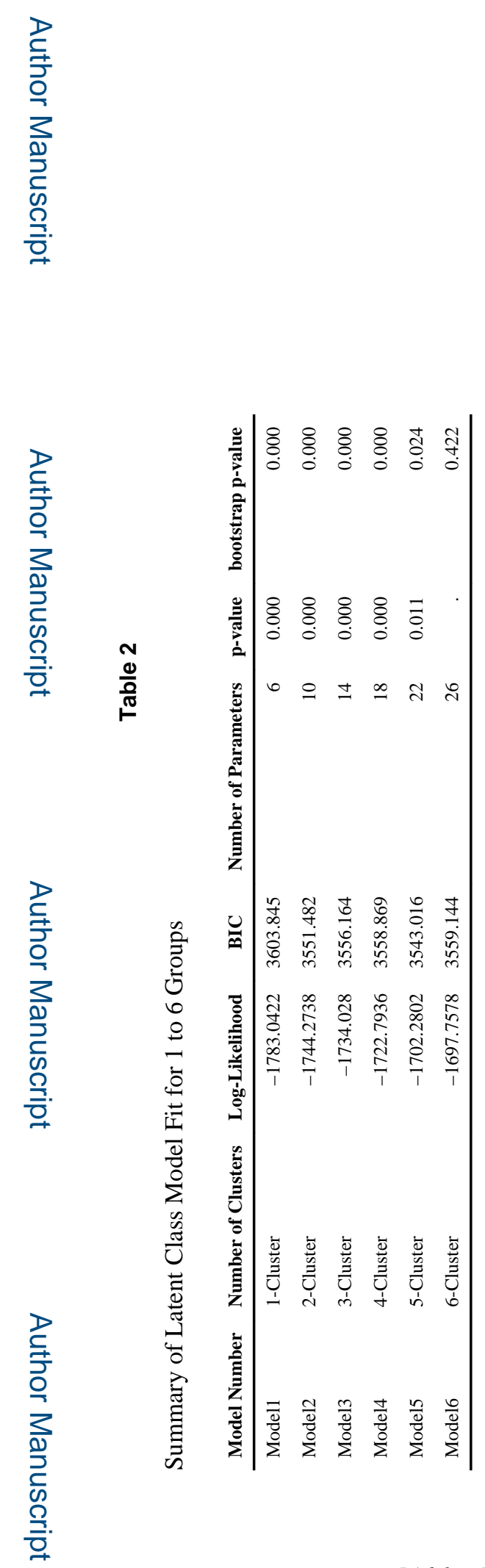

J Adolesc Health. Author manuscript; available in PMC 2016 May 01. 


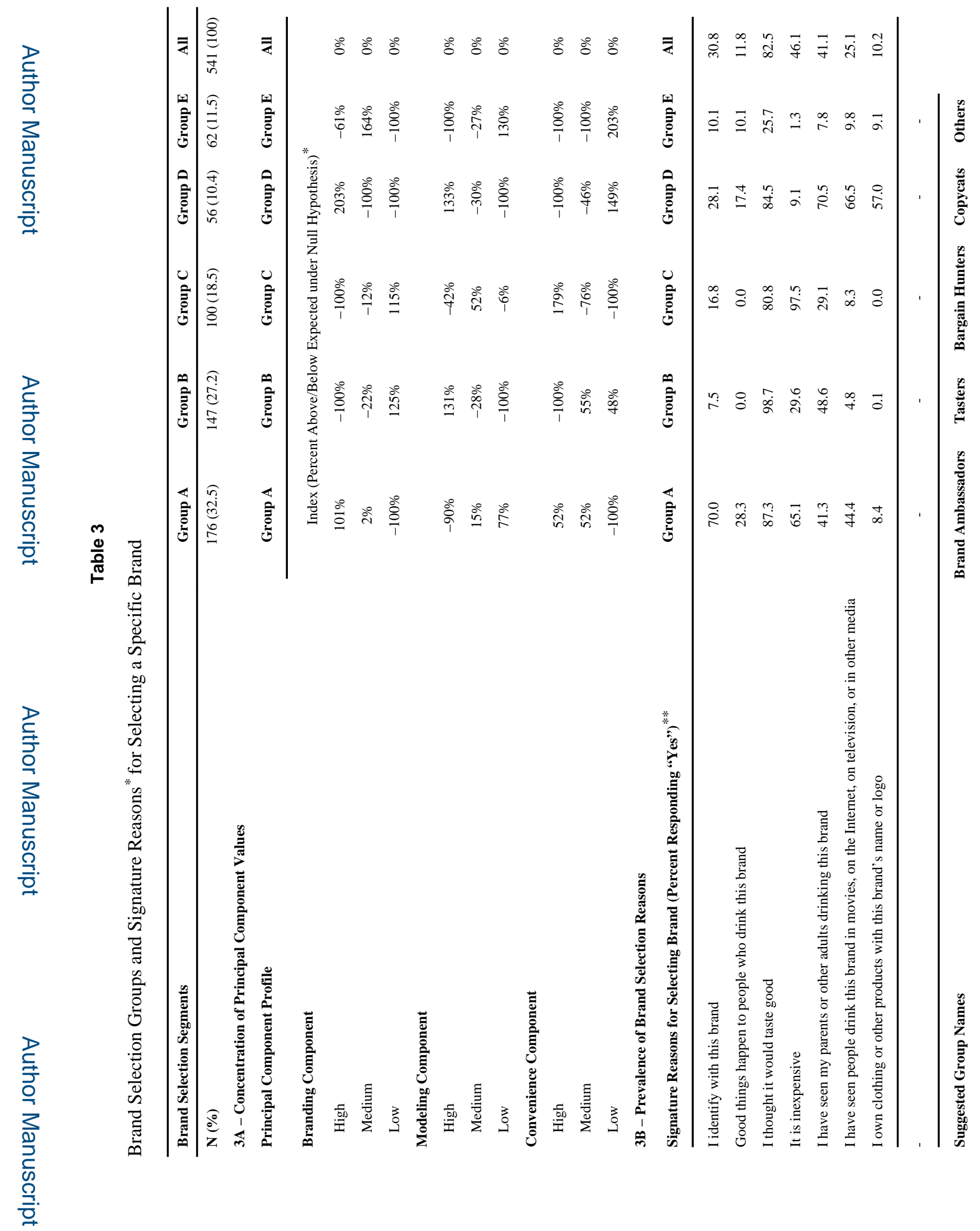

J Adolesc Health. Author manuscript; available in PMC 2016 May 01. 


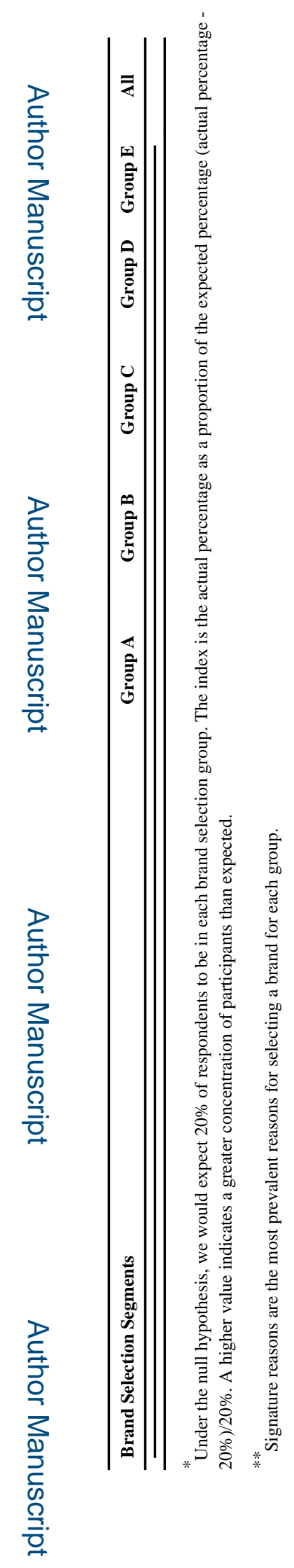

$J$ Adolesc Health. Author manuscript; available in PMC 2016 May 01. 
Ross et al.

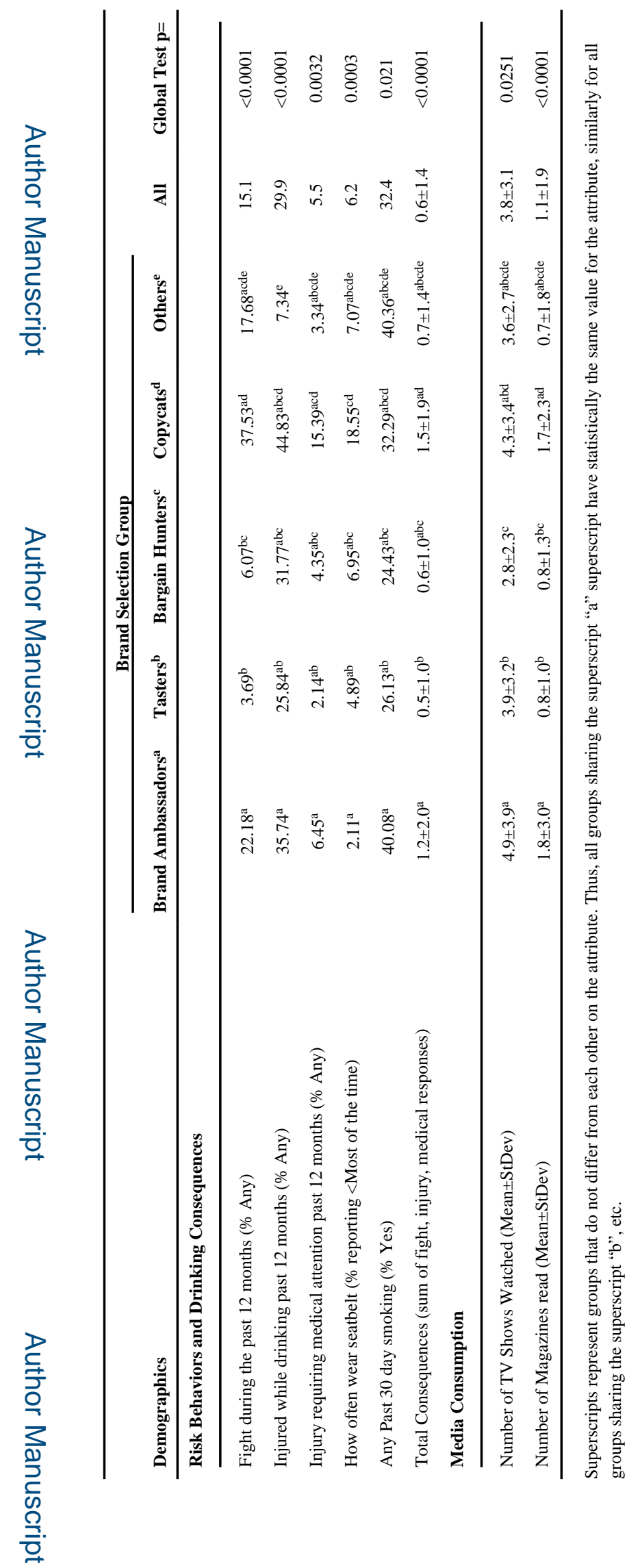

J Adolesc Health. Author manuscript; available in PMC 2016 May 01. 